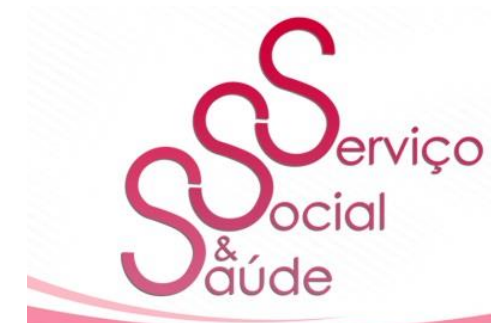

ISSN 2446-5992

(1) (1) (-)

$10.20396 /$ sss.v20i00.8668180

\title{
RESENHA
}

\section{Micropolítica e saúde: produção do cuidado, gestão e formação}

\section{Micropolitics and health: production of care, management and training}

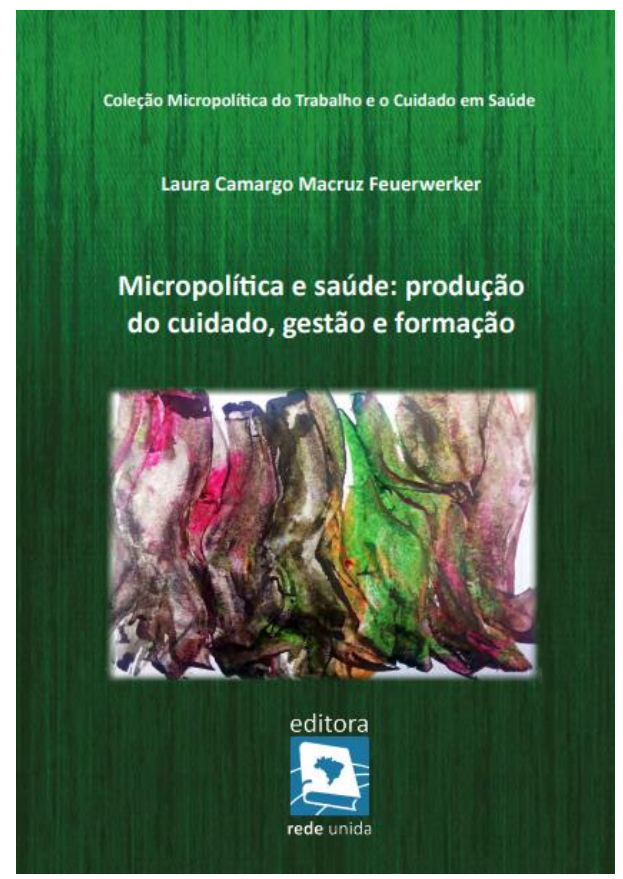

Francisca Maria Carvalho Cardoso ${ }^{1}$

FEUERWERKER, Laura Camargo

Macruz. Micropolítica e saúde: produção do cuidado, gestão e formação. Porto Alegre, RS: Rede Unida. 2014. 174 p.

ISBN: 978-85-66659-19-1

${ }^{1}$ Doutoranda pelo Programa de Pós-Graduação em Políticas Públicas da Universidade Federal do Piauí (UFPI) na Linha Cultura, Identidade e Processos Sociais. Membro do Grupo de Estudo e Pesquisa Formação, Trabalho, Desigualdade Social e Políticas Públicas, CNPq, Brasil. Telefone: 5586 99922-2814. E-mail: franciscamariacardoso@gmail.com. 
obra Micropolítica e saúde: produção do cuidado, gestão e formação (2014) de

autoria de Laura Camargo Macruz Feuerwerker se ancora no conceito filosófico de micropolítica à luz de Gilles Deleuze, Félix Guattari e Michel Foucault. A autora apresenta o conceito de micropolítica como processo de produção de subjetividades a partir das relações de poder na produção do cuidado, na gestão, na educação permanente e na formação em saúde. A autora discute o processo de construção do Sistema Único de Saúde (SUS), a Reforma Sanitária no Brasil, a constituição de redes de atenção em saúde, a consolidação dos modelos tecnoassistenciais do SUS e a gestão em saúde. Analisa ainda, a importância da educação permanente em saúde enfatizando a complexidade das mudanças na formação dos profissionais.

No tópico 1 intitulado Por onde vou andar neste material, a autora faz referência aos filósofos Deleuze, Guattari e Foucault, assinalando a importância para a sua formação, das experiências marcantes no encontro com suas obras, principalmente, a experiência relacionada a Emerson Merhy. A autora apresenta as inquietações presentes no decorrer dos estudos de Medicina, em sua residência e na Revista Saúde em Debate. Assinala a trajetória percorrida no mestrado, no doutorado e nas pesquisas sobre formação em saúde, bem como as inquietações da formação no que tange à relação com a construção do próprio Sistema Único de Saúde.

No tópico 2, Ressonâncias de Foucault, Deleuze e Guattari em meu pensamento, enfatiza a importância das contribuições de suas perspectivas de análise e a necessidade de aprofundar os temas da formação, da reinvenção da vida e de sua defesa, da produção do saber na relação com o outro. Esses autores, a partir de suas escolas filosóficas, enfatizam que a vida é uma relação com o mundo, que é movida por uma "produção desejante" (FEUERWERKER, 2014, p. 22), sendo a produção do homem no mundo uma ação política.

No tópico 3, Micropolítica do trabalho e o cuidado em saúde, a autora assinala a relevância da parceria com Emerson Merhy, apresentando o seu conceito de tecnologias de cuidado e a utilização das caixas de ferramentas visando contribuir para a compreensão do conceito de tecnologias de cuidado em Saúde. Explica ainda que, na sua perspectiva de análise, a micropolítica é entendida como um plano molecular no qual ocorrem os processos de subjetivação, colocados em prática partir das relações de poder.

\begin{tabular}{|l|l|l|l|l|l|} 
Serv. Soc. \& Saúde & Campinas, SP & v. 20 & e021013 & 2021 & e-ISSN 2446-5992 \\
\hline
\end{tabular}


O trabalho em saúde é uma produção social e de cuidado, que ocorre no encontro entre trabalhador e usuário, uma vez que neste encontro marcado pela ação territorial, há a expectativa do usuário de ser cuidado pelo profissional. Nesta dinâmica, o próprio território é um componente importante na produção do cuidado que se materializa através deste encontro, uma vez que, nele há a possibilidade do estabelecimento de vínculo, de corresponsabilização do profissional pela saúde do usuário que, sente a interação a partir do momento que é escutado, sendo esta parceria realizada em prol da construção do plano de cuidados.

Feuerwerker assinala que as práticas de saúde, como toda atividade humana, são atos produtivos. Nas palavras da autora, ancorada na perspectiva de Merhy (2009), há três tipos de caixas de ferramentas que o profissional da saúde utiliza, a primeira diz respeito ao manuseio dos equipamentos necessários para seu exercício clínico, incluindo os exames e até os medicamentos, são as chamadas tecnologias duras. Numa segunda caixa é construído o olhar do trabalhador em saúde sobre seu usuário, fundado nos saberes definidos em cada profissão, são as tecnologias leve-duras. A terceira caixa de ferramenta se refere às relações do trabalhador no encontro com o usuário. Nesta caixa encontram-se as tecnologias leves que se efetivam a partir do encontro entre usuário e trabalhador de saúde, mediante o vínculo estabelecido, o interesse do profissional pela situação do usuário e a definição da forma através da qual o profissional poderá intervir.

É no território que se dá o encontro do profissional com o usuário em presença das três caixas de ferramentas que estão presentes nos serviços e na dimensão cuidadora. Outro ponto a destacar, consiste na presença das relações de poder nos espaços dos serviços de saúde que acontece, tendencialmente, pela lógica dos poderes políticos, técnicos e administrativos. Dessa forma, cabe destacar a centralidade na figura do médico ainda como saber hegemônico em detrimento das demais profissões.

No tópico 4, intitulado Micropolítica e a política e a gestão em saúde, a autora analisa a produção da área, enfatizando a realidade nas unidades de saúde, onde planos são produzidos em fluxos intensos de comunicação, de conexão dos processos produtivos, ficando evidenciada a importância de os profissionais de saúde apreenderem o trabalho como modo de produzir vida e, portanto, como produção da micropolítica do trabalho vivo.

A autora salienta que o trabalho em saúde é uma arena onde estão presentes diversos atores. Nesse contexto, cada trabalhador e usuário tem ideias próprias, sendo que os gestores

\begin{tabular}{|l|l|l|l|l|l|} 
Serv. Soc. \& Saúde & Campinas, SP & v. 20 & e021013 & 2021 & e-ISSN 2446-5992
\end{tabular}


cumprem um papel decisivo nessas práticas, principalmente, no que tange às condições materiais oferecidas, contudo, os gestores não governam sozinhos, por isso a importância da gestão compartilhada, da produção do cuidado que requer criticidade e a ampliação das relações de trabalho dos profissionais e gestores.

No subtópico 4.1 Modelos tecnoassistenciais, gestão e organização do trabalho em saúde: nada é indiferente no processo de luta para a consolidação do SUS. A autora destaca o movimento da Reforma Sanitária, como um movimento múltiplo, em defesa do direito à saúde e à vida. Esse movimento se articulou e trabalhou com as ideias de democracia, universalidade, equidade em prol da construção do SUS. Destaca ainda, a presença do modelo neoliberal como fruto do Capitalismo, no cenário mundial e nacional, sendo, neste período, que o SUS se consolida no Brasil.

Nessa perspectiva, a autora enfatiza que há um núcleo de atores envolvidos nesse debate intenso voltado para a fabricação do SUS para todos. Nesse contexto, os modelos que visam organizar a atenção à saúde são essenciais para a consolidação do SUS, para qualificar o cuidado, efetivar as tecnologias e operacionalizar a integralidade como conceito-chave.

A autora, no subtópico 4.2, discute a Educação Permanente em Saúde: educação, saúde, gestão e produção do cuidado, enfatizando a importância do processo de Educação Permanente iniciado nos anos de 1930, na Europa, primeiramente no campo da Educação. Dialoga com as ideias de Furter, que afirma que o homem está em constante construção e que o saber científico é somente uma parte desses saberes possíveis. Essas ideias tiveram como inspiração a obra do educador brasileiro, Paulo Freire, e o seu método de alfabetização de adultos, pensando a educação como um ato libertador. Nesta perspectiva de análise, a Educação Permanente seria uma estratégia pedagógica.

A autora destaca que o Departamento de Gestão da Educação do Ministério da Saúde, a Rede Unida e a Educação Popular em Saúde incorporaram inovações à Educação Permanente. Assinala a importância da Educação Permanente como possibilidade de valorizar a dimensão pedagógica do trabalho e a relação de aprendizagem do trabalhador com base no seu próprio agir, nas suas práticas e nas práticas da gestão em saúde.

A compreensão do trabalho vivo em atos, segundo Feuerwerker, pressupõe o reconhecimento da relação do próprio trabalho compreendido como um ato vivo, que pede a participação de todos no espaço do trabalho vivo e de sua reinvenção. É nesse processo de

\begin{tabular}{|l|l|l|l|l|l|} 
Serv. Soc. \& Saúde & Campinas, SP & v. 20 & e021013 & 2021 & e-ISSN 2446-5992 \\
\hline
\end{tabular}


práticas, compartilhamentos, que acontece o trabalho vivo em ato e onde a educação permanente se materializa. A autora afirma que a EPS é, ao mesmo tempo, uma estratégia pedagógica e de gestão.

No subtópico 4.3 intitulado A construção de Redes de Atenção à Saúde numa perspectiva cuidadora e com a integralidade como referência, Feuerwerker discute a construção de redes. No SUS, as redes de atenção não são recentes e produzem arranjos que articulam o acesso a diferentes tipos de serviço. O tema das redes se articula às necessidades de saúde que são amplas, principalmente, no que tange ao fundamento do direito à saúde para todos. Enfatiza que as tecnologias leves estão presentes neste contexto, sendo essencial o estabelecimento de relação entre os saberes, a acolhida, o vínculo e a gestão da produção do cuidado.

Nesse sentido, a efetivação das redes é importante para a articulação e a gestão. A autora enfatiza a relevância de se analisar o contexto médico-hegemônico que muitas vezes predomina no contexto da saúde. Nesse espaço, as redes têm fundamental importância, uma vez que permitem mapear, identificar problemas e definir projetos com base no apoio institucional e matricial.

O tópico 5, Micropolítica e a formação de profissionais de saúde tem como base a tese de doutorado de Feuerwerker. Nele, a autora assinala que a formação dos profissionais foi seu primeiro campo de interesse na produção acadêmica. Na pesquisa de mestrado empreendeu a análise da residência médica e do seu papel para a formação do profissional da área. Na pesquisa de doutorado analisou duas experiências na graduação de Medicina, que contribuíram para pensar os desafios das mudanças no processo de formação.

O subtópico 5.1 denominado A complexidade de mudar a formação - algumas lições aprendidas, trata das experiências dos últimos anos no Brasil que demonstram os desafios para mudar a formação dos profissionais de saúde. A autora assinala que há muitas universidades e escolas voltadas para a formação desses profissionais, no entanto, cumpre assinalar a existência de disputas entre as "máquinas conceituais que os movimentos de mudança e as políticas de saúde conseguiram fabricar" (FEUERWERKER, 2014, p. 121).

Assinala ainda um cenário de disputas, entre o setor privado e o SUS, ou seja, entre um Sistema que é produzido pelas forças do Movimento da Reforma Sanitária e o SUS produzido pela indústria dos medicamentos. Existe um SUS nas pequenas cidades 
empobrecidas e um SUS em cidades de regiões com grande circulação de capital. Há o SUS produzido pelo Ministério da Saúde e um SUS produzido pelas secretarias estaduais de saúde. "Esses são apenas alguns dos SUS ativamente produzidos por distintos atores sociais e que compõem, em tensão, a configuração do SUS real"'(FEUERWERKER, 2014, p. 121). Desse modo, a autora assinala a necessidade de um processo de mudança que também depende de um agir.

No subtópico 5.2, As políticas para mudar a formação, a autora destaca algumas propostas de práticas inovadoras na saúde, como a: Cooperação entre o Ministério da Saúde e o Fórum de Pró-Reitores de Extensão, a Cooperação entre o Ministério da Saúde e as diferentes Associações de Ensino, a Cooperação direta entre o Ministério da Saúde e as instituições de ensino superior da área da Saúde, a Cooperação entre o Ministério da Saúde e o movimento estudantil, a constituição dos Polos de Educação Permanente em Saúde, a Formação de Ativadores de Processos de Mudança na graduação das profissões da Saúde, além da formação de facilitadores de educação permanente, a formação de ativadores de mudança, o VER-SUS e as Residências Multiprofissionais em Saúde, ainda destaca o PróSaúde e o Programa de Educação pelo Trabalho (PET). A autora destaca ainda que devido às Diretrizes Curriculares Nacionais para as profissões da Saúde foi possível construir diversas formas de inovação para a formação na Saúde.

No subtópico 5.3, sob o título Qual é e como tem sido fabricada a agenda das mudanças na formação a autora aponta que a partir da Conferência de Alma Ata (1978), a participação da Atenção Primária na Saúde (APS) se fez mais presente e iniciou um marco importante para as modificações na formação e para uma integração mais ativa do profissional no trabalho em saúde, contribuindo para a participação de profissionais com saberes distintos em cenários de aprendizagem diversos, através de metodologias ativas, que não constituem um fim em si mesmas, mas uma ferramenta importante para professores, estudantes e trabalhadores da saúde produzirem movimentos autoanalíticos e novas possibilidades de produção do conhecimento.

Nas considerações finais, no tópico denominado Para seguir adiante, Feuerwerker afirma que as políticas, a produção do cuidado e a formação constituem possibilidades para a tessitura de diálogos que permitem a produção na docência, na graduação, na pósgraduação, nas pesquisas, além de imprimir direção para a construção de um cuidado mais efetivo.

\begin{tabular}{|l|l|l|l|l|l|} 
Serv. Soc. \& Saúde & Campinas, SP & v. 20 & e021013 & 2021 & e-ISSN 2446-5992 \\
\hline
\end{tabular}


A obra apresenta importantes contribuições para o trabalho em saúde, uma vez que valoriza a produção do cuidado, a educação permanente, a formação profissional, a gestão além de enfatizar, a importância do trabalho em saúde e de suas tecnologias na efetivação do encontro do usuário com o serviço, com o profissional na busca do fortalecimento do Sistema Único de Saúde visando efetivar a defesa da vida.

Recebido em dezembro de 2021 - Aprovado em dezembro de 2021.

\section{REFERÊNCIA}

FEUERWERKER, Laura Camargo Macruz. Micropolítica e saúde: produção do cuidado, gestão e formação. Porto Alegre, RS: Rede Unida, 2014, 174 p. ISBN: 978-85-66659-19-1 